Received: 27 Februari 2019

Revised: 22 Maret 2019

Accepted: 28 Maret 2019

Published: 28 Juni 2019

\title{
RELIABILITAS SISTEM DENGAN PENDEKATAN NONPARAMETRIK
}

\author{
Izzati Wulandari $^{1, \text { a) }}$, Suyono ${ }^{2, \text { b) }}$, Widyanti Rahayu ${ }^{2, c)}$ \\ ${ }^{1}$ Program Studi Matematika, Fakultas Matematika dan Ilmu Pengetahuan Alam, Universitas Negeri Jakarta \\ ${ }^{2}$ Program Studi Statistika, Fakultas Matematika dan Ilmu Pengetahuan Alam, Universitas Negeri Jakarta \\ Email: ${ }^{a)}$ izzatiwulandari29@gmail.com, b) synjkt@yahoo.com, ${ }^{c}$ widyanti.rahayu @gmail.com
}

\begin{abstract}
This study discusses the reliability of the system with a nonparametric approach, namely the failure time of a component is not modeled with a particular parametric distribution. With this approach first derived Laplace transformation from system reliability, which contains the Laplace Stieltjes transformation from the failure time of a component. Furthermore, by using the empirical distribution function of realization data, this Laplace transformation is numerically inversed using the help of mathematical software. In addition, this study also discusses the reliability of the series system with a nonparametric approach.
\end{abstract}

Keywords: system reliability, nonparametric, empirical distribution function, Laplace transformation, series system reliability.

\begin{abstract}
Abstrak
Penelitian ini membahas mengenai reliabilitas sistem dengan pendekatan nonparametrik, yaitu waktu kegagalan suatu komponen tidak dimodelkan dengan distribusi parametrik tertentu. Dengan pendekatan ini pertama-tama diturunkan transformasi Laplace dari reliabilitas sistem, yang memuat transformasi Laplace Stieltjes dari waktu kegagalan suatu komponen. Selanjutnya dengan menggunakan fungsi distribusi empirik dari data realisasi, transformasi Laplace ini diinversi secara numerik dengan menggunakan bantuan software matematika. Selain itu, dalam penelitian ini juga membahas reliabilitas sistem seri dengan pendekatan nonparametrik.
\end{abstract}

Kata-kata kunci: reliabilitas sistem, nonparametrik, fungsi distribusi empirik, transformasi Laplace, reliabilitas sistem seri.

\section{PENDAHULUAN}

Dalam suatu sistem terdapat sekumpulan komponen yang saling berkaitan dan mempengaruhi untuk mencapai tujuan yang sama. Jika salah satu komponen rusak, maka sistem akan bekerja kurang 
maksimal ataupun gagal dalam mencapai tujuannya. Selain itu, untuk menghubungkan setiap komponen yang ada dibutuhkan suatu rangkaian, salah satunya rangkaian seri. Rangkaian seri berfungsi jika semua komponennya berfungsi, sehingga setiap komponen memiliki kinerja yang berperan penting dalam menunjang kinerja sistem. Untuk mengetahui kinerja sistem tersebut, dapat dilihat dari nilai reliabilitasnya.

Secara umum, reliabilitas merupakan peluang suatu komponen atau sistem akan berfungsi dengan baik dalam periode waktu dan kondisi tertentu. Selain itu, pada reliabilitas terdapat beberapa distribusi yang dapat digunakan sesuai dengan data yang ada. Jika model distribusi populasi suatu data diketahui, maka reliabilitas sistem bisa ditentukan melalui pendekatan parametrik. Jika data yang digunakan tidak memiliki model distribusi tertentu, maka reliabilitas sistem bisa ditentukan melalui pendekatan nonparametrik.

Secara matematis, suatu komponen yang berfungsi dengan baik dalam periode waktu tertentu disebut sebagai umur atau waktu kegagalan. Misalkan waktu kegagalan suatu komponen dinyatakan sebagai variabel acak $T$, maka reliabilitas pada waktu ke $t$ dapat didefinisikan sebagai peluang waktu kegagalan yang lebih besar dari $t$. Persamaan integral yang terdapat dalam fungsi reliabilitas sistem pada umumnya sulit dihitung secara langsung, untuk mengatasinya maka dapat ditransformasikan dengan transformasi Laplace. Hasil yang diperoleh kemudian diinversi agar mendapatkan fungsi reliabilitas kembali.

Penelitian yang dilakukan oleh Tae Hee Lee pada tahun 2003 membahas tentang reliabilitas untuk sistem mekanik yang bekerja di area yang tidak dapat diakses. Lee menyimpulkan bahwa estimasi pada nonparametrik lebih disarankan karena menghasilkan galat pada reliabilitas lebih sedikit dibandingkan dengan estimasi pada parametrik. Penelitian ini membahas mengenai reliabilitas sistem dan reliabilitas sistem seri dengan pendekatan nonparametrik.

\section{METODE}

\section{Variabel Acak}

Fungsi $P: F \rightarrow[0,1]$ disebut fungsi probabilitas jika memenuhi

$$
0 \leq P(A) \leq 1, \forall A \in F
$$

dan

$$
P\left(\bigcup_{i=1}^{\infty} A_{i}\right)=\sum_{i=1}^{\infty} P\left(A_{i}\right)
$$

Jika $\left(A_{n}\right) \in F$ merupakan barisan himpunan yang saling lepas, atau $A_{i} \cap A_{j}=\varnothing, i \neq j$.

Misalkan $(S, F, P)$ merupakan ruang probabilitas, fungsi $\mathbb{R}$ disebut variabel acak jik untuk setiap $a \in \mathbb{R}$, himpunan $X^{-1}([a, \infty]) \in F$

$$
\{\omega \in S: X(\omega) \geq a\} \in F
$$

\section{Distribusi Empirik}

Pada ilmu statistik, fungsi distribusi empirik adalah perkiraan fungsi distribusi kumulatif yang menghasilkan titik-titik dalam sampel. Dimana setiap titik dalam sampel memiliki nilai probabilitas sebesar $1 / n$. 
Misalkan $X_{1}, X_{2}, \ldots, X_{n}$ adalah sampel acak berukuran $n$ dari suatu populasi, dan diurutkan sehingga $X_{(1)} \leq X_{(2)} \leq \ldots \leq X_{(n)}$. Jika setiap $X$ independen dan berdistribusi secara identik, maka fungsi distribusi empirik didefinisikan sebagai berikut.

$$
F_{n_{X}}(x)=\left\{\begin{array}{lr}
0, & x<X_{(1)} \\
\frac{i}{n}, & X_{(i)} \leq x<X_{(i+1)} \\
1, & x \geq X_{(n)}
\end{array}\right.
$$

\section{Reliabilitas}

Misalkan variabel acak $T$ menunjukkan umur atau waktu kegagalan pada suatu komponen, yang dimulai dari awal komponen beroperasi sampai dengan terjadinya kegagalan (failure) pertama tanpa perbaikan, maka reliabilitas dari suatu komponen pada waktu $t$ didefinisikan sebagai berikut.

$$
\begin{aligned}
R_{T}(t) & =1-F_{T}(t), \text { untuk } t>0 \\
& =\int_{t}^{\infty} d F_{T}(x)
\end{aligned}
$$

Jika terdapat variabel acak $T_{i}$ yang saling bebas (independen), dimana $T_{i}$ menyatakan komponen ke- $i$ pada sistem, maka fungsi waktu kegagalan pada sistem seri $Y$ yang terbentuk adalah.

$$
Y(T)=\min \left(T_{1}, T_{2}, \ldots, T_{n}\right)
$$

Apabila pada sistem seri terdapat dua variabel acak, yaitu variabel acak $T$ dan $U$ yang menunjukkan waktu kegagalan komponen 1 dan 2, maka fungsi distribusi kumulatif dari $Y(T)$ dengan notasi $T_{Y}(t)$ dapat dinyatakan sebagai berikut.

$$
\begin{aligned}
F_{Y}(t) & =P[\min (T, U) \leq t] \\
& =1-R_{T}(t) R_{U}(t)
\end{aligned}
$$

Sehingga diperoleh fungsi reliabilitas sistem seri dari 2 komponen, yaitu sebagai berikut.

$$
\begin{aligned}
R_{Y}(t) & =1-F_{Y}(t) \\
& =R_{T}(t) R_{U}(t)
\end{aligned}
$$

\section{Transformasi Laplace dan Inversinya}

Misalkan $f(t)$ merupakan fungsi bernilai riil dengan $t>0$, maka transformasi Laplace dari fungsi $f(t)$ didefinisikan sebagai berikut.

$$
\hat{f}(s)=\int_{0}^{\infty} e^{-s t} f(t) d t
$$

dimana $s$ merupakan variabel kompleks, disaat nilai integralnya ada.

Apabila $\hat{f}(s)$ diketahui, maka fungsi $f(t)$ dapat dicari dengan menggunakan rumus inversi pada transformasi Laplace sebagai berikut.

$$
f(t)=\frac{e^{a t}}{2 \pi} \int_{-\infty}^{\infty} e^{i t u} \hat{f}(a+i u) d u
$$

Dengan $i=\sqrt{-1}$ dan $a$ adalah bilangan riil yang dipilih sedemikian hingga $\hat{f}(s)$ tidak memiliki titik singular di sebelah kanan atau pada garis vertikal $s=a$. Secara umum inversi transformasi Laplace tidak bisa langsung didapat menggunakan metode analitik, maka untuk memperoleh solusinya 
digunakan metode numerik. Salah satu cara yang dapat digunakan untuk mengaproksimasi integral secara numerik adalah aturan trapesium.

Jika terdapat suatu fungsi $g$ pada interval tertutup $[c, d]$, maka dapat diaproksimasi dengan aturan trapesium sebagai berikut.

$$
\int_{c}^{d} g(x) d x \approx h\left[\frac{g(c)+g(d)}{2}+\sum_{k=1}^{n-1} g(c+k h)\right]
$$

dengan $h=\frac{d-c}{n}$.

Jika $c=-\infty$ dan $d=\infty$ serta aproksimasi dari fungsi $g$ yang terintegralkan pada seluruh garis riil, maka rumus di atas menjadi

$$
\int_{-\infty}^{\infty} g(x) d x \approx h_{1} \sum_{k=-\infty}^{\infty} g\left(k h_{1}\right)
$$

dengan $h_{l}$ adalah suatu konstanta positif yang cukup kecil.

Dengan menerapkan rumus (3) terhadap (2), serta mengambil $h_{l}=\pi / t, t>0$, dan $a=A / t$, maka diperoleh

$$
f(t) \approx \frac{e^{A}}{2 t} \hat{f}\left(\frac{A}{t}\right)+\frac{e^{A}}{t} \sum_{k=1}^{M}(-1)^{k} \operatorname{Re}\left[\hat{f}\left(\frac{A+i \pi k}{t}\right)\right]
$$

persamaan di atas digunakan untuk menginversi transformasi Laplace secara numerik, menggunakan bantuan software matematika.

\section{Transformasi Laplace-Stieltjes}

Terdapat fungsi $f$ yang terintegral Stieltjes terhadap $g$ pada $[a, b]$, disimbolkan dengan $f \in S_{g}[a, b]$.

Teorema 1. Fungsi $f \in S_{g}[a, b]$ pada $[a, b]$ jika dan hanya jika untuk setiap $\varepsilon>0$ terdapat suatu partisi $P$ sehingga

$$
U(P, f, g)-L(P, f, g)<\varepsilon
$$

Misalkan $F(t)$ adalah fungsi yang terdifinisi dengan baik dari $t$ untuk $t \geq 0$ dan $s$ adalah bilangan kompleks, maka berdasarkan persamaan (1) diperoleh transformasi Laplace-Stieltjes dari $F(t)$ sebagai berikut.

$$
F^{*}(s)=\int_{0}^{\infty} e^{-s t} d F(t)
$$

\section{HASIL DAN PEMBAHASAN}

\section{Integral Stieltjes terhadap Distribusi Empirik}

Misalkan terdapat suatu fungsi g pada interval tertutup [a,b] yang diintegralkan terhadap fungsi distribusi empirik $F_{n_{x}}$ pada interval yang sama, maka integral Stieltjes terhadap distribusi empirik dinyatakan sebagai berikut.

$$
\int_{0}^{\infty} g(x) d F_{n_{X}}(x)=\frac{1}{n} \sum_{i=1}^{n} g\left(x_{(i)}\right)
$$




\section{Integral Stieltjes terhadap Fungsi Reliabilitas}

Misalkan pada partisi fungsi distribusi empirik dengan interval $[0, \infty)$ terdapat waktu kegagalan dari suatu komponen $t$ dengan $R(t)=\int_{t}^{\infty} d F_{X}(x)$ maka berdasarkan Gambar 1 berikut.

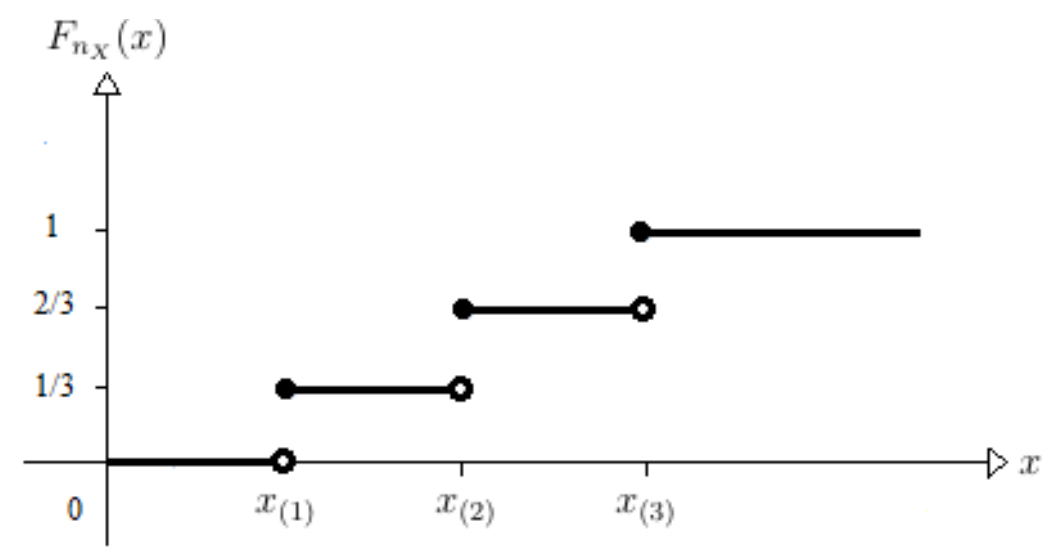

GAMBAR 1. Grafik Fungsi Distribusi Empirik

Berdasarkan diagram pada gambar 1 di atas, diperoleh reliabilitas suatu komponen pada waktu ke $t$ sebagai berikut.

$$
R_{T}(t)=\left\{\begin{array}{lc}
1, & \text { jika } 0 \leq t \leq x_{(1)} \\
\frac{2}{3}, & \text { jika } x_{(1)}<t \leq x_{(2)} \\
\frac{1}{3}, & \text { jika } x_{(2)}<t \leq x_{(3)} \\
0, & \text { jika } x_{(3)}<t \leq \infty .
\end{array}\right.
$$

\section{Reliabilitas Sistem dengan Pendekatan Nonparametrik}

Dalam menghitung reliabilitas sistem $R_{T}(t)$ secara langsung sulit dilakukan, dikarenakan fungsi yang terbentuk rumit dan tidak bisa menggunakan rumus-rumus aljabar yang sudah ditentukan. Untuk mengatasinya maka digunakan transformasi Laplace dari fungsi $R_{T}(t)$ sebagai berikut.

$$
\begin{aligned}
\int_{0}^{\infty} R_{T}(t) e^{-s t} d t & =\int_{t=0}^{\infty} \int_{x=t}^{\infty} d F_{n_{T}}(x) e^{-s t} d t \\
& =\frac{1}{s}\left[1-F_{n_{T}}^{*}(s)\right]
\end{aligned}
$$

Misalkan terdapat $T_{(1)} \leq T_{(2)} \leq \ldots \leq T_{(n)}$ yang merupakan sampel acak terurut dari waktu kegagalan suatu komponen $T_{1}, T_{2}, \ldots, T_{n}$. Jika $T_{i}$ memiliki data realisasi $t_{i}$, maka dengan persamaan (5) diperoleh transformasi Laplace-Stieltjes terhadap distribusi empirik sebagai berikut.

$$
\begin{aligned}
F_{n_{T}}{ }^{*}(s) & =\int_{0}^{\infty} e^{-s t} d F_{n_{T}}(t) \\
& =\frac{1}{n} \sum_{i=1}^{n} e^{-s t_{(i)}}
\end{aligned}
$$


Substitusikan persamaan (7) ke dalam persamaan (6), maka diperoleh transformasi Laplace dari fungsi $R_{T}(t)$ sebagai berikut.

$$
\begin{aligned}
\int_{0}^{\infty} R_{T}(t) e^{-s t} d t & =\frac{1}{s}\left[1-F_{n_{T}}^{*}(s)\right] \\
& =\frac{n-\sum_{i=1}^{n} e^{-s t_{(i)}}}{n s}
\end{aligned}
$$

Untuk mendapatkan kembali fungsi $R_{T}(t)$ pada persamaan (8), maka dilakukan inversi transformasi Laplace secara numerik menggunakan persamaan (4) dengan bantuan software matematika.

Misalkan terdapat 5 data realisasi dari waktu kegagalan suatu komponen yang telah diurutkan, yaitu $t_{(1)}=0.5, t_{(2)}=1, t_{(3)}=1.5, t_{(4)}=2$, dan $t_{(5)}=2.3$. Dengan menggunakan software matematika, maka akan diperoleh hasil dari $R_{T}(t)$ yang dapat disajikan pada Gambar 2 sebagai berikut.

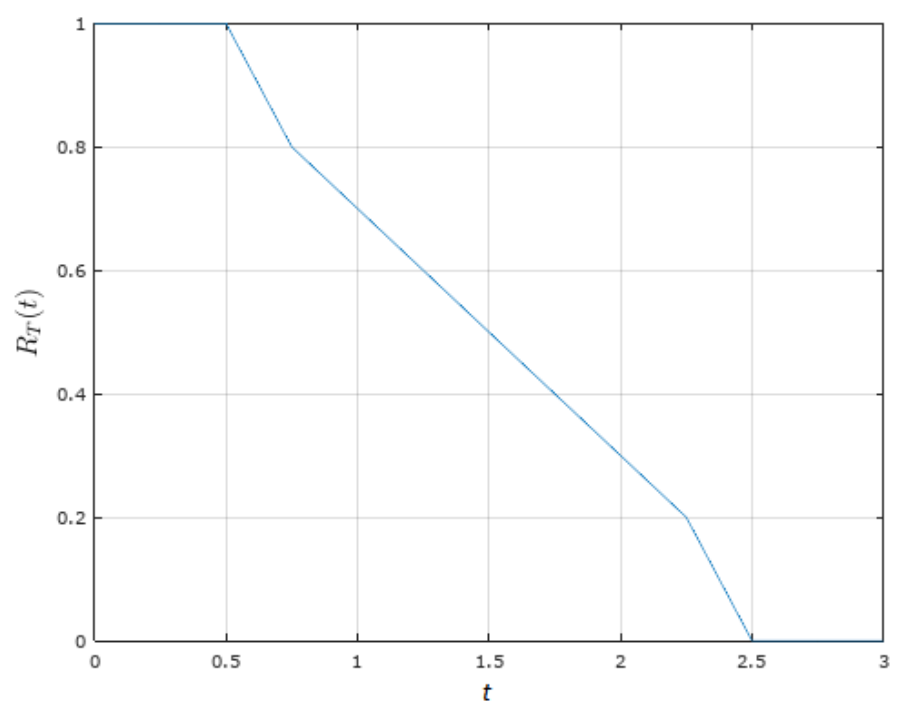

GAMBAR 2. Grafik Reliabilitas Sistem

Berdasarkan grafik tersebut, menurunnya nilai reliabilitas sistem disebabkan oleh nilai $t$ yang semakin meningkat. Hal ini sesuai dengan teori reliabilitas, dimana semakin lama sistem berfungsi, maka keandalan sistem tersebut akan semakin menurun hingga mengalami suatu kegagalan.

\section{Reliabilitas Sistem Seri dengan Pendekatan Nonparametrik}

Dalam menghitung reliabilitas sistem seri $R_{Y}(t)$ secara langsung sulit dilakukan, maka untuk mengatasinya digunakan transformasi Laplace. Transformasi Laplace dari fungsi $R_{Y}(t)$ sebagai berikut.

$$
\begin{aligned}
\int_{0}^{\infty} R_{Y}(t) e^{-s t} d t= & \int_{0}^{\infty} R_{T}(t) R_{U}(t) e^{-s t} d t \\
= & \frac{1}{s}-\int_{0}^{\infty} F_{n_{T}}(t) e^{-s t} d t-\int_{0}^{\infty} F_{n_{U}}(t) e^{-s t} d t+ \\
& \int_{0}^{\infty} F_{n_{T}}(t) F_{n_{U}}(t) e^{-s t} d t
\end{aligned}
$$

Pada reliabilitas sistem seri, untuk mendapatkan nilai $R_{Y}(t)$ dibutuhkan data realisasi terlebih dahulu. Misalkan terdapat 3 data realisasi pada tiap komponen, yaitu untuk komponen $T$ adalah $t_{(l)}=$ 1.1, $t_{(2)}=2.6$, dan $t_{(3)}=2.6$, untuk komponen $U$ adalah $u_{(1)}=1.7, u_{(2)}=2.3$, dan $u_{(3)}=3.5$. 
Maka dari tiap komponen dapat diketahui fungsi distribusi empiriknya sebagai berikut.

$$
\begin{gathered}
F_{n_{T}}(t)=\left\{\begin{array}{c}
0, t<t_{(1)}, \\
\frac{1}{3}, t_{(1)} \leq t<t_{(2)}, \\
\frac{2}{3}, t_{(2)} \leq t<t_{(3)}, \\
1, t_{(3)} \geq t .
\end{array}\right. \\
F_{n_{U}}(t)=\left\{\begin{array}{c}
0, t<u_{(1)}, \\
\frac{1}{3}, u_{(1)} \leq t<u_{(2)}, \\
\frac{2}{3}, u_{(2)} \leq t<u_{(3)}, \\
1, u_{(3)} \geq t .
\end{array}\right.
\end{gathered}
$$

Dari fungsi distribusi empirik $F_{n_{T}}(t)$ dan $F_{n_{U}}(t)$ dapat diperoleh fungsi $F_{n_{T}}(t) F_{n_{U}}(t)$, yaitu sebagai berikut.

$$
F_{n_{T}}(t) F_{n_{U}}(t)=\left\{\begin{array}{c}
(0)(0)=0, t<t_{(1)} \\
\left(\frac{1}{3}\right)(0)=0, t_{(1)} \leq t<u_{(1)} \\
\left(\frac{1}{3}\right)\left(\frac{1}{3}\right)=\frac{1}{9}, u_{(1)} \leq t<u_{(2)}, \\
\left(\frac{1}{3}\right)\left(\frac{2}{3}\right)=\frac{2}{9}, u_{(2)} \leq t<t_{(2)}, \\
\left(\frac{2}{3}\right)\left(\frac{2}{3}\right)=\frac{4}{9}, t_{(1)} \leq t<u_{(3)}, \\
\left(\frac{2}{3}\right)\left(\frac{3}{3}\right)=\frac{6}{9}, u_{(3)} \leq t<t_{(3)}, \\
(1)(1)=1, t_{(3)} \geq t .
\end{array}\right.
$$

Selanjutnya, akan dilakukan transformasi Laplace dari fungsi $F_{n_{T}}(t), F_{n_{U}}(t)$, dan $F_{n_{T}}(t) F_{n_{U}}(t)$.

a) Transformasi Laplace dari fungsi $F_{n_{T}}(t)$.

$$
\int_{0}^{\infty} F_{n_{T}}(t) e^{-s t} d t=\frac{e^{-s t_{(1)}}}{3 s}+\frac{e^{-s t_{(2)}}}{3 s}+\frac{e^{-s t_{(3)}}}{3 s}
$$

b) Transformasi Laplace dari fungsi $F_{n_{U}}(t)$.

$$
\int_{0}^{\infty} F_{n_{U}}(t) e^{-s t} d t=\frac{e^{-s u_{(1)}}}{3 s}+\frac{e^{-s u_{(2)}}}{3 s}+\frac{e^{-s u_{(3)}}}{3 s}
$$

c) Transformasi Laplace dari fungsi $F_{n_{T}}(t) F_{n_{U}}(t)$.

$$
\int_{0}^{\infty} F_{n_{T}}(t) F_{n_{U}}(t) e^{-s t} d t=\frac{2 e^{-s t_{(2)}}}{9 s}+\frac{3 e^{-s t_{(3)}}}{9 s}+\frac{e^{-s u_{(1)}}}{9 s}+\frac{e^{-s t_{(2)}}}{9 s}+\frac{2 e^{-s u_{(3)}}}{9 s}
$$

Substitusikan persamaan (10), (11), dan (12) ke dalam persamaan (9), sehingga diperoleh transformasi Laplace dari fungsi $R_{Y}(t)$ sebagai berikut:

$$
\int_{0}^{\infty} R_{Y}(t) e^{-s t} d t=\frac{9-3 e^{-s t_{(1)}}-e^{-s t_{(2)}}-2 e^{-s u_{(1)}}-2 e^{-s u_{(2)}}-e^{-s u_{(3)}}}{9 s}
$$


Untuk mendapatkan kembali fungsi $R_{Y}(t)$ pada persamaan (13), maka dilakukan inversi transformasi Laplace secara numerik menggunakan persamaan (4) dengan bantuan software matematika. Hasil yang didapat disajikan pada Gambar 3 sebagai berikut.

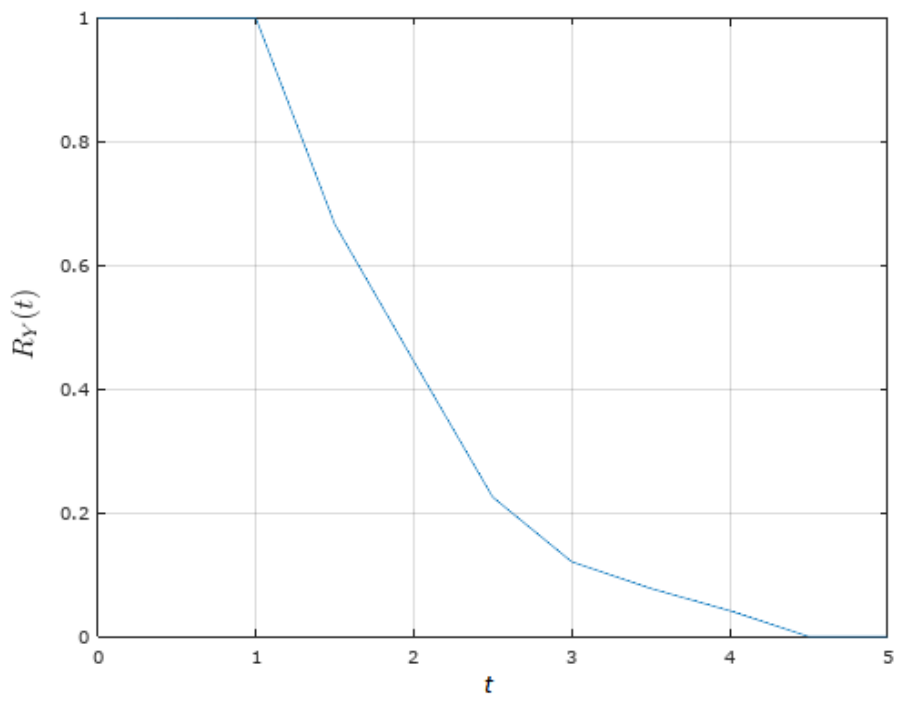

GAMBAR 3. Grafik Reliabilitas Sistem Seri

Berdasarkan gambar tersebut, menurunnya nilai reliabilitas sistem seri disebabkan oleh nilai $t$ yang semakin meningkat. Sehingga pada relabilitas sistem seri dengan dua komponen, sesuai dengan teori reliabilitas. Dimana semakin lama sistem berfungsi, maka keandalan sistem tersebut akan semakin menurun hingga mengalami suatu kegagalan.

\section{KESIMPULAN DAN SARAN}

\section{Kesimpulan}

1. Reliabilitas Sistem dengan Pendekatan nonparametrik.

Menghitung reliabilitas sistem dari $R_{T}(t)$ dengan cara menginversi transformasi Laplace ,yang dapat diaproksimasikan menggunakan bantuan software matematika.

$$
\int_{0}^{\infty} R_{T}(t) e^{-s t} d t=\frac{n-\sum_{i=1}^{n} e^{-s t_{(i)}}}{n s}
$$

2. Reliabilitas Sistem Seri dengan Pendekatan Nonparametrik.

Dalam reliabilitas sistem seri dibutuhkan data realisasi terlebih dahulu, misalkan komponen $T$ memiliki data realisasi $t_{i}$ dan komponen $U$ memiliki data realisasi $u_{j}$. Untuk menghitung reliabilitas sistem seri dari $R_{Y}(t)$ dengan cara menginversi transformasi Laplace.

$$
\int_{0}^{\infty} R_{Y}(t) e^{-s t} d t=\frac{9-3 e^{-s t_{(1)}}-e^{-s t_{(2)}}-2 e^{-s u_{(1)}}-2 e^{-s u_{(2)}}-e^{-s u_{(3)}}}{9 s}
$$

\section{Saran}

Penelitian selanjutnya disarankan untuk mengkaji lebih lanjut tentang reliabilitas sistem dengan pendekatan nonparametrik untuk sistem paralel. Selain itu, disarankan melakukan perbandingan antara 
reliabilitas sistem dengan pendekatan nonparametrik dan parametrik, serta perbandingan antara reliabilitas sistem dengan pendekatan nonparametrik untuk sistem seri dan paralel.

\section{UCAPAN TERIMA KASIH}

Terima kasih kepada Bapak Prof. Dr. Suyono, M.Si. dan Ibu Dra. Widyanti Rahayu, M.Si. atas saran dan ketersediaan waktu dalam membimbing penulis, sehingga tulisan ini berhasil selesai dengan baik.

\section{REFERENSI}

Bain, Lee J., Engelhardt, Max (1991) Introduction to Probability and Mathematical Statistics. Pacific Grove: Duxbury.

Beerends, R.J., ter Morsche, H.G., Van den Berg, J.C. and Van de Vrie, E.M. (2003) Fourier and Laplace transforms. Cambridge, UK: Cambridge University Press, p.458.

Capinski, M. and Kopp, P.E. (1991) Measure, integral and probability, USA: Springer Science \& Business Media.

Lee, Tae Hee et al. (2013) 'Nonparametric Reliability Analysis for Design of A Mechanical System Working on an Inaccessible Area', 10th World Congress on Structural and Multidisciplinary Optimization.

Loonker, Deshna (2016) 'Solution of Integral Equation and Laplace-Stieltjes Transform', Palestina Journal of Mathematics, Vol.5(1):43-49.

Munir, Rinaldi (2013) Metode Numerik. Bandung: Informatika.

Purcell, Edwin J., Vanberg, Dale, Rigdon, Steven E. (2007) Calculus 9th Edition. USA:Pearson Education.

Rausand, Marvin, Hoyland, Arnljot (2004) System Reliability Theory: Models, Statistical Methods, and Applications 2nd Edition. New York: John Wiley and Sons Inc.

Ross, Sheldon M. (2009) Introduction to Probability Models, Tenth Edition. New York: Academic Press.

Rudin, Walter (1964) Principles of Mathematical Analysis Third Edition. New York: McGraw-Hill, Inc.

Spiegel, Murray S. (1965) Schaum's Outline of Theory and Problems of Laplace Transforms. McGraw-Hill: USA.

Suherman (2017) Nilai Awal dan Syarat Batas. Yogyakarta: Deepublish.

Suyono. (2003) Renewal Processes and Repairable Systems, Dissertation, Delft University Press.

Ushakov, Nikolai G. (1999) Selected Topics in Characteristics Function. VSP: Utrecht, The Nederlands. 